\title{
Erratum to: Evaluation of two methods for the use of diatoms in drowning cases
}

\author{
Nadia Fucci ${ }^{1}$ - Vincenzo L. Pascali ${ }^{1}$. Camilla Puccinelli ${ }^{2}$ - Stefania Marcheggiani ${ }^{2}$. \\ Laura Mancini $^{2}$ - Daniela Marchetti ${ }^{1}$
}

Accepted: 21 August 2015 / Published online: 6 January 2017

(C) Springer Science+Business Media New York 2017

Erratum to: Forensic Sci Med Pathol (2015) 11:601-605

DOI 10.1007/s12024-015-9708-2

The original version of this article unfortunately contains mistakes in the figure captions. The correct versions are provided below:

Fig. 1 Photomicrograph of Cyclotella meneghiniana.

Fig. 2 Photomicrograph of Amphora ovalis.

Fig. 3 Photomicrographs of Navicula lanceolata.

The online version of the original article can be found at http://dx.doi. org/10.1007/s12024-015-9708-2

Nadia Fucci

nadiafucci@rm.unicatt.it

1 Section of Legal Medicine, Institute of Public Health, Università Cattolica del Sacro Cuore, Largo F. Vito, 1, 00168 Rome, Italy

2 Environment and Primary Prevention Department, Istituto Superiore di Sanità, Viale Regina Elena, 299, 00161 Rome, Italy 